\title{
Analysis on the Functions and Approaches of Promoting Innovation of Social Governance through Construction of Network Culture
}

\author{
Kuanmin LU, Ying LI \\ Ideological and Political Department of Xi'an University of Technology, Xi'an, 710048, China
}

\begin{abstract}
The 3rd Plenary Session of 18th CPC Central Committee has promoted to "innovate the social governance system", which is a new idea of social construction and also demonstrates the new changes in the top-level design of CPC's social administration. At present, social administration is closely linked with information networks. The popularization of network will bring new changes to the traditional way of social administration, providing it with new external variable. On the one hand, the network promotes the informatization level of social administration, improving cadres' ability of network politics, and expands the ways of public communication and the modes of social administration, changing its traditional pattern thoroughly; on the other hand, government should accommodate the rapidly development trend of Internet and make good use of the rules of network communication to conduct the decision, communication and coordination of social administration, thus improving the level of social administration by using the internet as a platform to ask what people suggest and want.
\end{abstract}

KEYWORD: Internet culture; Social administration; Innovative practice

The 3rd Plenary Session of 18th CPC Central Committee has promoted to "innovate the social governance system". With the proposition of this social construction idea, which emphasizes on safeguarding people's basic interests and improving the harmonious social factors and the vitality of social development, there indicates that the governance model of China are undergoing profound changes and the governing philosophy of CPC are improving greatly. Culture, as an important spiritual strength to educate and cultivate people, has played a significant role in the process of innovating social administration. Getting culture involved in innovating social administration can elevate citizens' cultural power and support the social development and civilization. Internet culture, as a whole new social culture mode, are accepted and recognized by most people. It has influenced our life, our learning and our way of communication deeply, giving us a new channel of establishing public culture service system and safeguarding people's basic rights. Therefore, promoting the social administration ability by cyber culture is both the new requirement and urgent task of innovating social administration.

\section{INTERNET CULTURAL CONSTRUCTION AND SOCIAL ADMINISTRATION INNOVATION}

Culture, in a board sense, means all the social activities' achievements of human beings that are different from the natural phenomena, including all the material and non-material products created by human ${ }^{1}$ The definition made by British anthropologist Edward.B.Tyler has a great influence. He argues that culture is a complex synthesis which includes knowledge, faith, art, morality, law, custom and all kind of abilities and habits that are gained by the members of the society. ${ }^{2}$ To put it simple, culture is all the achievements of social life since human beings were born. If we say that the history of human being is formed by some rules, then that's the cultural logic. In a sense, culture has played a decisive role in the construction of human society. Internet culture is also the same. It is a totally new culture pattern formed along with the Internet, which can be simply summarized as all the activities' achievements made by human in the Internet,

\footnotetext{
1 Zheng Hangshen. Introduction to Sociology Revised. Beijing: China Renmin University Press. 2009. P90.

${ }^{2}$ Tyler. Anthropology an introduction to the study of man and civilization. Interpreted by Lian Shusheng. Guilin: Guangxi Normal University Press. 2004. P7.
} 
gathering the practices of the network members in the cyber society. Up to December, 2013, the scale of Chinese netizens has reached 618 million with $45.8 \%{ }^{3}$ of Internet popularizing rate. All these data indicates that China has already entered the network era. Therefore, the development in the cyber culture will change every aspect of people's life, and what it brings are not only the scientific development, economic progress and cultural prosperous, but also the epitome of China's social development.

Promoting the social administration to social governance in the 3rd Plenary Session of 18th CPC Central Committee reveals the new variations in the top-level design of CPC's social administration. Governance, as a public management concept, was first appeared in the late 1990s, and it has been widely used since then. This word interprets that besides the effective organizational management, there are other fields relating to problem solving, including the management of local, domestic and international issues. Compared with social administration, social governance is more inclined to the parity, democracy and interactivity of the main body in the administration process. It not only clearly identifies the tendency, object and standard of power and decision, but also clarifies the origin of power, the introduction process of decision-making and the interactive relationship between each part of managerial structure. In a word, social administration is an art about controlling and guiding the society and the organizations. ${ }^{4}$ From social administration to social governance, though there is only one-word's difference, it shows the new characteristics of China's public management and the hopes of the people in the new period. In the process of social transformation centered on economic reform, the socialist market economic system have not completely established yet, leading to the occasional happening of the governmental offside and market absence. And the public service system which is closely linked to people's livelihood like education and medical care also has not finished yet, so that people cannot equally enjoy the results of reform and development. Especially, the corruption phenomenon and bureaucratism of some officers would result in the loss of public power's credibility and the centripetal force, making tense relationship between the cadres and the publics and harming people's feelings. People may then be reluctant to participate in the activities initiated by the Party and the government, and they may stand idle about the major issues relating to the national development and survival. If the mass population lose their vigor in participating in those activities, our dream of

\footnotetext{
3 China Internet Network Information Center: 33rd Statistical Report of China's Internet Development Conditions.

4 Ding Yuanzhu. Innovating the Social Governance and Stimulating the Vitality of Social Development. Frontline. 2013(12)
}

achieving the great rejuvenation of the Chinese nation will not be realized. Hence, promoting social administration to social governance is an effective measure to stimulate people's passion and vitality and lessen the power's intervention in the market. On the basis of perfecting the product market and factor market, it will help create the fair and equal development opportunities, encourage people's entrepreneurship and employment, support them to manage their own public affairs and mobilize their initiative to the greatest extent. And the multi-level, multi-factor and three-dimensional process of innovating social governance should not only consider the factors like society, politics and economy, but also be combined with the mainstream values and social and moral cultures. In the Internet age, innovating the social governance cannot be successful without a sound and prosperous network culture.

Information network is the important carrier for spreading advanced culture, proving public cultural service and enriching spiritual and cultural life in China. In today's competition of cultural soft power in the digital information age, Internet culture occupies a significant position and has also become an important part of our cultural construction. Network information is transnational, and information stream guides the flow of technology, capital and talents. Information resources have gradually became the vital production factor and social wealth. The degree of information control now is a major signal of the nation's soft power and competitiveness. Information network is actively pushing forward the preparing and improving of socialist market economy, democratic politics, advanced culture, harmonious society and ecological civilization, etc., which will definitely has great influence on the social administration. The construction of Internet culture, which has already been a significant factor of innovating the social governance, is now expanding the ways of public opinion communication and the patterns of social governance, thus becoming the most active productivity factor in the change of times. At present, China is in the key period of economy transition and social transformation, bringing all kinds of social contradictions. Therefore, it makes the social governance more difficult.

The Internet should have all kind of voices, and the culture should be shared by all mankind. CPC central committee has researched on the issues of strengthening and innovating social administration for several times, and innovating is what they emphasize. Making use of the Internet to conduct social administration and coordination is a kind of innovation that is in accordance with the times. That requires the exploration of new thoughts and new paths of social governance. Internet society is different from the real world, which is a relatively 
free space for speech. Inside of it, there exists various types of cultures, ideologies, values, living standards and moral rules. CPC central committee has noticed the important role the Internet has played in China's socialist cultural construction for a long time, and made clear requirement that "we need to strengthen and improve the management of information network, and advance the managerial level of virtual society." In the aspect of innovating social administration, the report of the 18th National Congress points out that "we should speed up the formation of the social administration system that is led by the Party committee, in the charge of government, cooperated with the society, participated by the citizen and protected by the law. " It also requires that "we should boost the scientific level of social administration, and must strengthen the construction of the law, mechanism, ability, talent team and informatization of social administration." Social governance participated by the Internet is an inevitable innovation.

In recent years, the Internet cultural undertaking and cultural industry with Chinese characteristics has maintained the momentum of all-round rapid development. While continuously fulfilling people's ever-growing spiritual and cultural demands and pushing forward the economic and social development, Internet culture has also participated in the social governance effectively. Internet culture is and will continue to deeply influence the development of mankind, shouldering heavy responsibility in the social governance with its strong advantages. It is a common sense of practice now to utilize Internet as a social and political communication tool in the process of social governance. The socialization of network has realized the blending of Internet and reality. Only by abiding the operational rules of Internet and the wills of the public, can the docking of the Internet and the reality and the playing of the Internet's function be successful, thus proving an efficient service for social governance. By the construction of the cyber culture, we can give the full play of the positive energy of Internet, utilize its cultural power to improve the ability of social governance and turn the socialization of network into a potential productivity of innovating the social governance. Meanwhile, through continuous strengthening of the cyber cultural construction, the active role it plays in the innovation of social governance will be put in a good use, thus the populace's cultivation and educational level can be further improved to meet the cultural demands of people.

\section{FUNCTIONAL ORIENTATION OF INTERNET CULTURE IN THE PROCESS OF INNOVATING SOCIAL GOVERNANCE}

In short, the purpose of social governance is to guarantee the coordinated and orderly development of social activities, social life and social relationship by harmonizing social interests and resolving social contradictions, making the social system stay in a good operation state and realizing the optimization of social development's result. The main function of culture is the norm, integration, enlightenment, communication, cognition, inheritance, aggregation and entertainment. In the Internet era, the social reform and progress will not achieve without the guidance and promoting of the healthy network culture. The innovation of social governance, which also requires a good ideological and cultural condition, is the same.

\subsection{The development of Internet culture deepens the connotation of social governance.}

Currently, China is in the transformation process. The outstanding feature of the process is the fragmentization of social structure, which is the fragmentation, diversion and multi-direction of the social structure and the form of organization. It poses higher demands against the social governance, first is the separation of powers in essence, second is the multielement of the main body, and third is the multidirectional activities of the pattern. ${ }^{5}$ As an outcome of network society's development, the Internet culture's major feature is its participatory, and that feature conforms to the decentralization, pluralism and interaction of innovating social governance. With the development of China's economy and the strengthening of public's independent consciousness and political awareness, Internet becomes a new way for the people to report and propose to the Party and the government, and also a platform for people to conduct social service and social supervision, providing the channel for them to express their views and demands. Internet is beneficial to smooth the construction of interestexpressing mechanism, perfect the public service network and expand the expressing access of public opinion. Now, more people gain the information firstly from the Internet, and express their views in it. CPC Central Committee pays high attention to the network information and seriously deals with the major realistic problems reported by the netizens. Starting from the small questions and listening the voice from the grass roots are the bond for maintaining close ties with the masses, which will

\footnotetext{
${ }^{5} \mathrm{Lu}$ Yu. Cultivating and Practicing Socialist Core Values in the Innovation of Social Governance [EB/OL].

http://www.qstheory.cn/lg/jcsc/201402/t20140219_322465.htm, Feb $19^{\text {th }}, 2014$.
} 
help to improve the Party's governing capacity. To speed up network information construction is also an important pushing hand for expediting social governance and constructing the service-based government.

\subsection{The development of Internet culture enriches the ways of social governance.}

A harmonious and steady social environment is both the premise and guarantee of innovating social governance and the target of achieving it. In June,2008, during his visit to People's Daily, $\mathrm{Hu}$ Jintao, who was the General Secretary of the CPC Central Committee at that time, pointed out that "Internet has already became the distributing center of thoughts, cultures and information and the amplifier of public opinion. We should fully understand the social influence of the emerging media presented by the Internet." Under the background of innovating social governance, We should completely recognize that Internet has played an guidance role in social harmony and stability. We should utilize the Internet to do public opinion collection and analysis, monitor the running state of the society and guide the benign development of social opinion. Government should clearly master the trends of the opinions in the Internet, especially notice the tendency of malicious remarks, and take effective measures to function the Internet to eliminate the vulnerabilities. On the other hand, network supervision is now becoming an emerging method of supervision with quick response and great influence. We should better the network report and acceptance mechanism and perfect the clue application and feedback system, thus providing people a convenient and unimpeded supervision channel. The convenient Internet will bring benefits to the Internet information collection of anticorruption, providing more ways for people to participate in the anti-corruption work. The interaction and sharing in the Internet brings the distance between the reporter and the administrative authority closer, as well as the distance between the reporter and the media, thus improving the speed of information feedback effectively. In the exposed cases of corruption, many netizens choose to collect evidence and offer valuable information to the casehandling authorities via Internet, making the network supervision more powerful. No matter in implementing the eight-point code put forward by the CPC Central Committee or taking more measures to do anti-corruption, the Internet has played an irreplaceable role. Network supervision has already been a quick and effective measure to express social opinion, safeguard people's interest and fight against corruption.

\subsection{The development of Internet culture strengthen} the systematicness of social governance.

Internet has showed its great energy in the forming process of modern social public opinion. And whether the Party and the government can form a good interaction relationship with the netizens has became an significant indicator of examining the governance capacity of the Party and government. In recent years, the Internet, especially the Weibo, has played an important part in encouraging netizens to participate in the topic discussing and signal amplifying. Gathering and discussing in the Internet, these netizens give their own opinions about the truth of those public events and the social injustice and system deficiencies that may exist, and the following up reports by the traditional media will attract more social strengths and concerns, thus offering more options to solve the events and creating a better social atmosphere. By doing so, the government, judicial department and other departments and the public opinion will think highly of those events, and finally provide them with all kinds of remedial measures. This kind of processing mode that features the subsequent compensation and punishment could safeguard and guarantee the related personnel's interest. Viewed from the forms and methods of people's taking part in the social governance, online political participation has obvious technical characteristics. It is convenient and swift with other features like substantivity and equality. Moreover, it is cheap to use. The Internet is providing us with more modes of political life and ways of communication. It shortens the distance between the government and the masses, so it is also a channel for the government to connect with people. The government can motivate people's enthusiasm in participating in the political affairs by formulating and implementing the network democratic participation plan, improve the responsive capability inside the political system by sharing the political decision information, political feedback information and the social service information, and bring closer the distance between political system, society and citizens by utilizing the network information technology. The masses can take part in the social administration via the Internet and support the government to make scientific decisions with a more active attitude. The government can also conduct equal consultation and dialogue and ask for people's suggestion via the Internet, thus realizing the effective management of social affairs.

\section{STRENGTHEN INTERNET CULTURAL CONSTRUCTION AND PROMOTE SOCIAL ADMINISTRATION INNOVATION}

"Internet culture should focus on the construction." Strengthening the construction of network culture is 
a key component in reinforcing the construction and management of socialist Internet culture with Chinese characteristics. While facing the new opportunities and challenges, we must fully understand the importance of strengthening the Internet cultural construction. So under the background of complicated social governance, how can we give the full play of the advantages and functions of Internet cultural construction to innovate the social construction and social governance, and to better serve the overall situation of reform, development and stability?

\subsection{Constructing the Internet culture that pools the wisdom of the people to provide intellectual support for serving the social governance.}

In the Internet era, the survival of mankind faces the dual situation of the real and virtual world. The masses are not only the main body of the development and consumption of Internet culture but also the subject of social governance services. Therefore, we should insist on and respect the pioneering spirit of people in the course of Internet cultural construction, pay high attention to people's enthusiasm, initiative and creativity and give the full play of the originality, diversity and universality of the cyber culture, thus guiding the main body of the cyber culture to provide good advice for the strengthening and innovating the social governance and play their role as the talent pool or the think tank. We can use the Internet to collect people's ideas on solving the problems relating to social governance, and adopt people's rational opinions and suggestions about pushing forward the innovation of social governance, thus gradually strengthening the social vitality and achieving the harmonious unification of social governance.

\subsection{Constructing the Internet culture that centers on livelihood issues to gather power for serving the social governance.}

Safeguarding and improving people's livelihood is the core issue and priority of social governance. It requires us to try our best to solve the livelihood issues relating to people's basic life. The construction of Internet culture should keep close links with the masses, and its work should be in accordance with current social reality. It should deeply reflect the prominent problems that would affect the social harmony and stability and the direct and realistic interest issues that people concern most about, such as education, employment, income distribution, social insurance, medical care, housing security, safety production, poverty relief and development, etc. Only by doing so can it attract the attention from the society to commonly discuss the ways to solve major social problems and to make the joint efforts from both the Internet and the real world to do social governance, thus actively coordinating the interests and needs of different parties and uniting strengths for serving the social governance.

\subsection{Constructing the Internet culture that promotes equality, rationality and containment to form a better interactive mechanism for serving the social governance.}

The social governance in the modern times depends on the administrator, the administration object and the good interactive relationship between the two. We should give the full play of the openness, equality and containment of the Internet culture, cultivate citizens' good attitudes featuring rationality, peace, openness and containment, and organize and guide the citizens to participate in the network politics orderly. By doing so, the network politics will become the "through train of public opinions", forming a sound democratic culture in the Internet. The government sectors and the public institutions should further improve the work methods, actively build the platform for information, communication, politics inquiry and activities such as the blog, microblog, online communities and so on, and optimize the work mechanism. Besides, focusing on offering an smooth participation and service channel, the government sectors and the public institutions should also constantly enlarge the social openness and involvement of the social governance, expand the channels of handy service for the public and the fields and range of social governance, thus forming a nice social governance mechanism that has a good interactive relationship between the administrative organizations and the public, and improving the scientific level of social governance.

\subsection{Constructing the Internet culture that shares the spiritual home to create a sound social atmosphere for serving the social governance.}

We need to make use of the unique superiority of using the Internet culture to inherit national classics, protect and carry forward our nation's outstanding traditional culture and build the brand of our culture to strengthen China's soft power and world's influence. We should focus on "the firm belief of walking on the road of socialist political development with Chinese characteristics" as the core, adhere to the guiding status of Marxism in the socialist advanced culture and share a healthy and harmonious online spiritual home. Besides, we have to identify and fight against the false information made by "online water army" and "online pushing hands", clean the information environment in the Internet, and promote the positive and healthy Internet culture to occupy the dominant position online. Moreover, we should create a favorable 
environment for innovating Internet culture and making the emergence of wonderful cultural products, and give full play of the Internet culture's function to guide the society, educate the people and promote the development, thus creating a good social environment for the realization of the economic and social development goals set for the Twelfth Five-Year Plan.

In order to strengthen the construction of network information and promote the innovation of social governance, we need to improve our understanding about the Internet, have a full knowledge about the status quo of China's Internet culture development and make full use of legal, administrative, economic and other means to strengthen the construction and effective management of the Internet. In the Decision of the CCCPC on Some Major Issues Concerning Comprehensively Deepening the Reform, it points out that "we will improve institutions and mechanisms that are conducive to upholding the correct orientation of public opinion. We will improve a linkage mechanism that integrates basic management, content management, industrial management, combats and prevents online criminal acts, improve the mechanism for dealing with online emergencies, and bring into being a framework of public opinion that combines positive guidance with management by law." We should fully understand the importance of the construction and management of the Internet information. From the perspective of governing capacity, institutional regulations, cultural security and social stability, we should build, utilize and manage the Internet well and adhere to the principle of Party's control over the media, thus pushing forward the development and reform with the construction and innovation. Strengthening the construction and management of network information is not only a long term task, but also a realistic problem waiting to be solved. We must fully understand the Internet culture, make a comprehensive development plan that involves information technology and network technological research, and make great efforts to solve the problem of scientific achievements' transformation. We need to introduce policies to support the development of enterprises, so that they could become the subject of technological innovation and the development of information industry. We should pay close attention to enact legislative plan, improve the Internet information management, critical information infrastructure protection and other related laws and regulations, govern the cyberspace by law, and safeguard the legitimate rights and interests of citizens. Moreover, we should greatly develop the Internet culture with Chinese characteristics, thus providing a platform for innovating social governance.

\section{ACKNOWLEDGEMENT}

Author: Kuanmin Lu, professor and doctoral supervisor of Xi'an University of Technology; Ying Li, graduate student of Xi'an University of Technology. Contact Person: Kuanmin Lu, telephone: 13363983288; E-mail: 1km@xaut.edu.cn; address: mailbox 218, Ideological and Political Department of Xi'an University of Technology Qujiang Campus, Yanxiang Road No.58, Xi'an City, 710048

\section{REFERENCES}

[1] Decision of the CCCPC on Some Major Issues Concerning Comprehensively Deepening the Reform. Beijing: People's Publishing House, 2013.

[2] Lu Kuanmin, Qiao Xiayang. Introduction of the Construction of Internet Virtual Society —-Reflection on Rule of Law and Moral Education. Beijing: People's Publishing House, 2013.

[3] Cui Wei. Management of Internet Society Requires the Use of Both Hard and Soft Tactics. Guangming Daily, Oct 20th, 2013.

[4] Tao Peng. Management of Virtual Society in the Perspective of Internet Culture. Theory and Reform, Feb, 2013.

[5] Network Culture Office of Shandong Province. Construction and Management of Internet Culture. Shandong: People's Publishing House, Aug, 2009.

[6] Gao Hongling. Online Public Opinions and Social Stability. Xinhua Press, Feb, 2012.

[7] Ma Li. Do the Guidance of Online Public Opinions in the Internet Era. People's Daily, Dec 27th, 2013.

[8] Ni Yangjun. Strengthening and Innovating Social Management Should Start With the Internet GMW.cn, Jun 12nd, 2011. 